\title{
Biological weapons, genetics, and social analysis: emerging responses, emerging issues-II
}

\author{
BRIAN RAPPERT \\ Sociology, University of Exeter, Exeter, EX4 4QF, UK.
}

\begin{abstract}
Recent terrorist attacks in the United States have generated significant attention in many countries to the threats posed by biological weapons. In response to these events and the specter of future attacks, bioscientists and professional organizations have begun or intensified asking questions about the possible malign applications of their research. Part II of this two-part article examines the emerging responses initiated by biomedical organizations and spokespersons in the US and the UK. In doing so it considers how scientific and medical research communities are defining and policing notions of professionalism, responsibility and accountability in the responses made. Through an examination of these issues, suggested lines for future social analysis are offered.
\end{abstract}

Part I of this two-part article examined how current genetics and genomics research might contribute to the development of biological weapons as well as the breadth of previous social analyses offered regarding bioweapons. This second part follows on by surveying initial responses by scientific and medical communities to the growing societal concern with the possibility that biology and genetics might enable new forms of weapons. It does so with a view to asking two questions:

- What is the range of responses being considered to mitigate against the threats identified?

- How are notions of professionalism, responsibility, and accountability defined through these responses?

\section{Emerging science policy responses}

With the increased attention to biological weapons, leading scientific bodies and spokespersons in the US and the UK are visiting or revisiting questions about what sort of response should be made by the biomedical communities. This is not a simple undertaking. However horrific the potential of mass casualties from bioweapons, in contemplating possible preventative and response measures,

Correspondence to: Brian Rappert, Sociology, University of Exeter, Exeter, EX4 4QJ, UK. Email: B.Rappert@exeter.ac.uk 
such fears need to be weighed against assessments of the feasibility of attack. The extent of measures undertaken should be in proportion to the threat perceived. If agreement were widespread about this, then the proper response would be more straightforward. As suggested in Part I, however, this is not the case. In relation to the somewhat contested space about biological weapons, this section examines prominent commentary made about the governance of biomedical research, this in relation to what agendas should be pursued, what professional advice is being given, and what restrictions might be placed on the access and dissemination of research. The related topics of the control of pathogenic material and access to laboratories have been subject to much recent deliberation and legislation elsewhere (see Epstein, 2001; HMSO, 2002; ASM, 2002; Malakoff, 2002b).

In addressing controls on the production and communication of research, it is first perhaps prudent to recognize calls for the 'silencing' of science in general, or biotechnology fields in particular, for reasons of national security are hardly unprecedented (Relyea, 1994). Nor, of course, are demands that scientists consider the wider societal implications of their work. Prior to recent events, when commentators in the biomedical community have reflected their social responsibility in relation to biological weapons, prominent suggestions have included various public and policy servicing roles such as raising public awareness, advising policy makers about threat assessments, encouraging responsible conduct and ethical appreciation in students, and establishing appropriate laboratory conditions for handling dangerous pathogens and toxins (e.g., Kadlec et al., 1997; FAS, 2000). Perhaps to a degree not found in any other fields, there have been widespread calls to recognize the outright abhorrence of bioweapon applications (e.g., Meselson, 2000a). The British Medical Association (1999, p. 101), for instance, recommended that:

[p]rofessional scientists and physicians have an ethical responsibility to reinforce the central norm that biological and genetic weapons are unacceptable. This should be explicitly stated in codes of professional conduct in order to safeguard interests in matters of health and safety.

Such statements are intended to support the BTWC prohibition on biological agents or toxins that have no justification for prophylactic, protective or other peaceful purposes.

As with the BTWC, in professional discussions about social responsibility, 'biodefense' has occupied a shadowy space where competing interpretations have been given about its acceptability and definition. Few have advocated a halt to such research, let only civilian studies of naturally occurring infectious diseases that might aid in the basic understanding of virulence. Yet the potential for defensive research to further offensive capabilities has meant some express unease about the wisdom of taking part in biodefense work. In the early 1990s, the US Council for Responsible Genetics started a pledge for scientists not to participate knowingly in research and teaching that will further the development of chemical and biological agents' (Wright, 1990, p. 412). To what extent 
biodefense should be included in such calls is likely to be matter of significant disagreement where much turns on shifting empirical assessments regarding the ability to separate defensive and offensive research or on attributions about the motivations for activities. After decades of disputes within the American Society for Microbiologists, in 1985 it adopted a code of ethics that discouraged 'any use of microbiology contrary to the welfare of humankind' (Cassell et al., 1994, p. 233), which rather left unanswered the very question of exactly what kind of research should and should not be done. Even within the biodefense community, there has been some recognition of the need to ask reflexive questions about what sort of enterprise defense establishments (such the US Army Medical Research Institute of Infectious Diseases) are engaged in and what ends might (however inadvertently) be served by their activities (e.g., Zilinskas, 1992).

The anthrax attacks in 2001 arguably has served as a punctuating point for debates about what ought to be done by the biomedical community vis-à-vis biodefense research. At least in the US, there is now a simple dominant answer given to questions about what research should be done: that being more. To be sure, in the years prior to September 2001, funding for biodefense had gone up significantly (Marshall, 1997; Wheelis, 2001). In 2001 the National Institutes of Health (NIH) commissioned $\$ 47$ million worth of $\mathrm{R} \& \mathrm{D}$ and $\$ 93$ million in 2002, both decisions made prior to 11 September (US Department of State, 2002). In the aftermath of events, funding for 'terrorism-related R\&D' across defense, health, energy, and transportation agencies was tripled (Malakoff, 2002a). The National Commission on Terrorism (2001) recommended a comprehensive and co-ordinated $\mathrm{R} \& \mathrm{D}$ program to counter biological threats.

In this spirit, the 2003 Presidential budget proposal contains $\$ 6$ billion for bioterrorism responses, including funds to improve local and state hospital capacity to deal with a bioterrorist attack, to enhance co-ordination between state and federal services, and to further the stockpiling of drugs. Some $\$ 2.5$ billion of that is earmarked for research and development of new treatments and new diagnostic, medicines and vaccines. This is intended to repair 'major inadequacies in [the] existing medical "toolkit" for fighting bioterrorism' (US Department of State, 2002). $\$ 1.75$ billion of it is allocated to the National Institutes of Health for basic and applied research into understanding biological pathogens. The National Institute of Allergy and Infectious Disease (NIAID) will play the leading role for the NIH. The NIAID Strategic Plan for Biodefense Research (NIAID, 2002), sub-titled Responding through Research, outlines its plans. The major focus will be on so-called category casual agents for smallpox, anthrax, botulism, tularemia and plague. The six major sections of research include biology of the microbe, host response, vaccines, therapeutics, diagnostics and research resources. Advances in genomics and proteomics were identified as having a key part in developing new targets for treatment and diagnostics.

With these substantial sums of money being dedicated to countering 
bioweapons, a significant reverse is taking place, at the least at level of justifying policy, regarding the benefits of research into infectious disease. Whereas in the past protection against biological attack was a secondary benefit provided by public health infrastructures and funding, today biodefense preparedness is said to offer 'spin-off' benefits for understanding the basic mechanisms of infectious diseases (see Balmer, 2002 for interesting historical parallels). Major scientific institutions in the US are now actively strategizing to ensure not only that significant funds are dedicated to $\mathrm{R} \& \mathrm{D}$, but also that this is channeled in the right directions - such as providing funds for basic research (as in Knobler et al., 2002) - and that the right sorts of organizations control the lion's share of funding - health rather than security related organizations such as the Department of Homeland Security (Malakoff, 2002c).

\section{Openness and controls}

Beyond funding level determinations, crucial concerns exist about if and how the production and communication of research should be controlled. Biomedical knowledge may be treated as a vital resource requiring significant funding, but it is double-edged. With renewed vigor, some are voicing questions about whether certain research should be classified, publications ought to be restricted or delayed, review boards should comment on the national security implications of certain activities, or whether there are topics that should not be investigated. While there is a long history of controls and limitations being imposed on research for reasons of national security, the past impetus for them has tended to derive from those within security agencies. Post-11 September, there is at least an ostensible questioning about the wisdom of the communication of even basic research and the responsibilities of those in the biomedical community (Malakoff, 2001). In a lead editorial, the Lancet Infectious Diseases (2001, p. 287) asked 'whether the days of open and free exchange of ideas are over for infectious diseases.'

With this increasing soul searching, potentially contentious issues must be addressed about the relation and the possible sources of conflict between national security and scientific research. Gerald Epstein (2001, p. 337) of the Institute of Defense Analyses has characterized the basic tension as such:

Governance mechanisms based on the potential application of a given line of research are difficult to reconcile with the established practice of the international scientific community, which attaches great importance to academic freedom, to free and open inquiry, and to protecting an individual investigator's ability to let scientific promise alone determine the direction in which research should evolve ... Preventing the distribution of completed and scientifically valid research would run counter to the norms of the scientific community, and it would inevitably impair the progress of science.

Often in the past, and with some degree of success, many in the scientific 
community and elsewhere have tried to resolve concerns about the balance of the free exchange of (unclassified) knowledge and unfettered pursuit of research versus national security restrictions by collapsing the tension between the two (see Alberts, 1999). Herein the suggestion is made to stay ahead of any potential risks by technical superiority rather than attempting to police research. Secrecy in Western countries would set and unfortunate example for the rest of the world and may well hinder attempts to fight infectious diseases. Matthew Meselson (1989, in Zilinskas \& Wilson 1992, pp. xiii-xiv), a long time campaigner about the dangers of biological weapons, argued:

Openness in all biological research has advantages that far outweigh any risk. It makes US policy credible. It helps recruiting and keeping the most talented investigators and in exposing shoddy work and misguided lines of research. Openness accelerates progress through the kind of scientific interchange characteristic of health sciences. Finally, by minimizing mutual suspicions, openness makes it possible for more nations to coordinate their efforts to combat disease and guard against infringements of the prohibition of biological and toxin weapons.

In this vein, the Australian government reportedly commenting on the wisdom of the mousepox manipulations noted above by saying 'the best way to protect misuse of this technique was to issue a worldwide warning' (Epstein, 2001, pp. 335-6). Such sentiments have taken form as formal policy. In relation to biothreats, the 1985 American Society for Microbiology code of conduct calls for 'microbiologists to communicate knowledge obtained through discussions with their peers and through publications in the scientific literature' (Halvorson, 1992). Similar conclusions were expressed in the 1985 US National Security Decision Directive 189 (in Epstein, 2001, p. 341), which prescribed that:

[The US'] leadership position in science and technology is an essential element in our economic and physical security. The strength of American science requires a research environment conducive to creativity, an environment in which the free exchange of ideas is a vital component ... To the maximum extent possible, the products of fundamental research [should remain] unrestricted.

To be sure, such instructions were not taken imply classification was unnecessary and, indeed, the Directive did not stop various forms of censure and control of 'fundamental' research in the 1980s (Dickson, 1984; Relyea, 1994). Much has depended on how directives are interpreted and implemented in practice.

Post-11 September, somewhat cautious public reaffirmations have been given to the importance of unfettered research and communication. For instance, editors of 11 American Society for Microbiology journals met in 2001 to ask what ethical and national security issues might compel them to reject publishing an article. The following consensus statement was drafted (Atlas, 2001):

The ASM recognizes that there are valid concerns regarding the 
publication of information in scientific journals that could be put to inappropriate use. The ASM hopes to participate in the public debate on these issues. Until a national consensus is reached, the rare manuscript that might raise such issues will be reviewed by the ASM Publications Board prior to the Society proceeding to publication.

In 2002 the president of the US National Academy of Sciences reiterated the importance of scientists providing knowledge as a public good in the face of high-profile knowledge proliferation concerns (Alberts, 2002).

Despite such statements, further controls have been agreed for greater restrictions on the handling of selective agents across many countries. In the US, limitations have been imposed on those persons able to work with potential bioterror agents and visas requirements are being use to screen out applications form foreign scientist to visit conferences in the US (Stone, 2002) or work in national labs (Enserink, 2002) - all the types of activities that brought derision during the Cold War for other fields. The National Academy of Sciences, through its Committees on Research Standards and Practice as well as International Security and Arms Control, is now deliberating what oversight institutional regimes might be necessary to ensure the legitimate use of research. The Office of Science and Technology Policy is separately considering what controls might be necessary for the dissemination of 'homeland security information'. In the past, for instance, John Steinbruner (2000)_Vice Chair of the Committee on International Security and Arms Control-suggested that international procedures could be developed for distributing funds, arrange priorities, conducting lab inspections protocols, and overseeing the voluntary but systematic release of information for research into the most dangerous pathogens.

Against the mounting calls for 'something to be done', arguments have been put forward that biomedical communities should attempt to develop their own structures of governance before others (read: 'politicians') do for them (and do it inappropriately-Poste, 2001; Epstein, 2001; Gewin, 2002). Here, reactionary legislative directives might impinge on many legitimate activities. The 1975 Asilomar conference about the safety of recombinant genetic engineering and subsequent voluntary moratoriums and formal guidelines (but not legislation) is said to serve as a useful model for thinking what could be done. The challenges in effectively implementing self-governance or other forms of control of research are formidable. Among these include the international spread of microbiology and biotechnology capabilities, the sheer amount of R\&D taking place in the public and private sectors, and the existence of other pressing priorities around the world. As 'offensive' development activities are already prohibited under the BTWC, it not clear how effective any self-governance measures might be in protecting against malign applications.

\section{Future research topics for consideration}

The last section outlined something of the emerging responses from biomedical 
communities and elsewhere regarding the necessary direction, intensity, and possible restrictions for research in fields such as microbiology, molecular biology, and genomics. Although the topic of biological weapons has received scant attention in the past in many social science fields, the substantial amount of research done regarding science, technology, and genetics does provide a basis for suggesting fruitful lines of research. In light of preliminary review in the last section, what possible inroads into the weaponization of biological research, and genetics in particular, might be offered?

It is perhaps prudent to start by acknowledging the diversity in the overall threat assessments and recommendations about appropriate responses. Much of the previous section considered US policy responses to biological weapons. It has been there that the most public discussions have taken place about what needs to be done. This is perhaps not surprising given the terrorist attacks of 2001, the relative lack of such incidents in US history, and the extent of biological research conducted in its borders. Considerable public funds are now being allocated against bioterrorism. Complementing this, much has been made of the urgency of the response required. Ronald Atlas (2001), President of the American Society for Microbiology, framed the threat as such: 'Never before has the biomedical community faced a greater challenge-protecting the public against infectious agents while facing heightened scrutiny over the misuse of science by terrorists'. In contrast, in the UK and elsewhere much less discussion has taken place about the imminent dangers posed by bioterrorism. Further legislative restrictions and penalties have been imposed and stockpiles of vaccines increased, but reactions have been much more low-key. The overall contrast no doubt owes much to the different evaluations made of necessary policy measures vis-à-vis the BTWC. The UK government has sought to address the threats of bioattacks through strengthening and extending the Convention's verification procedures as well as supplementary criminalization international agreements (HMSO, 2002). Arguably the US government's vision for the future of BTWC differs significantly from all other State Parties. Its current response is one of unilateral action, where as a result the range of responses debated extends beyond the terms of the BTWC. It is likely the origins and consequence of such distinct appraisals will be of no small public policy consequence in the future.

\section{Professional responsibility}

These large-scale differences in the threat identified and the types of responses sought are also likely to be consequential for notions put forward about the social responsibility of scientists and other professionals. Just whether and how scientists should take responsibility for the implications of their research has long been a matter of discussion. Varying models have been suggested; each that offers alternative evaluations of the status of knowledge as well as the breadth of 
ethical horizons (see Verhoog, 1981). So science can be seen as producing valuable and perhaps instrumental knowledge, but of a kind that neither contains nor entails a moral standing. Here ethical assessments only become relevant in the application of knowledge. For their part scientists should be responsibility to their peer community in the search for facts. Providing objective advice for decision-makers might be an important role that scientists could undertake, but ultimately they cannot be held responsible for the later applications of knowledge. In contrast, what might be identified as more critical or structural approaches contend scientists, like other professionals, are not just responsible for matters of accuracy. Instead, they need to consider the wider systems in which their work will be taken up and engage in debate about possible problems before these turn into acute social problems.

With the continuing prevalence of controversies about modern science and technology, value-neutral characterizations where a narrow interpretation is made of responsibility have generally gone out of favor, at least in public discussions about science-society relations. Gibbons (1999) has situated various challenges to the authority of science within the need for a new social contract. Traditional divisions and roles between university, government, and private research are no longer meaningful. In this, researchers must recognize the necessity of moving away from the production of 'reliable' to 'socially robust' knowledge. The latter depends on the incorporation of extended groups of experts (including lay experts) into the production of knowledge from the start of projects. For Gibbons, professionals are also challenged to think about the implications of their work (the so-called 'context of implication') and to develop new lines of communication to wider audiences.

At first glance, it would seem taking forward these suggestions in relation to biological weapons poses certain difficulties. The 'dual-use' potential of knowledge, the possible health benefits likely from a further understanding of microbiology and genetics, and the doubts about the feasibility of certain biological weapons, all make it difficult to evaluate the implications of particular lines of research. Research is just one piece of a complicated process of response and counter-response. That the topic of biological weapons has not had a high profile in the biomedical sciences means there are few widely known precedents that might guide action.

The general problems outlined in the second section of Part I about classifying and categorizing the protective or malign status of research would suggest that basic questions need to be asked about how scientists conceptualize the issues at stake and what this means for determinations of responsibility. Gieryn (1995), for instance, has detailed how scientists engage in a variety of 'boundary work' between divides such as objectivity/subjectivity, natural/social realms, and expert/lay knowledge in order to maintain control over the goals and standards of science. The often-expressed desire by scientists and other professionals to protect their relative autonomy shapes how scientific matters are distinguished from political ones. The basic tension is that science must be presented as close 
to political issues of the day in order to command funding, but not so close to invite outside inference in its governance.

Cunningham-Burley \& Kerr (1999) have investigated this dynamic of boundary work in relation to the construction of the social issues associated with genetic testing. The geneticists studied sought both cognitive authority necessary to justify funding, authority to comment on its social consequences, and yet-through selective and contingent accounts of the relation of science and society - to distance themselves from the responsibility for (negative) implications of genetics. Genetics was portrayed as both a disinterested practice and one very much concerned about social problems. Professional responsibilities were defined so to make researchers vital for addressing social problems but ultimately not responsible for them. So, geneticists should educate politicians and the public and help define the nature of public policy problems, but not actually be held responsible for 'abuses' of science (e.g., eugenics) which were deemed the fault of 'society'.

As Gieryn and others argue, boundaries such as those between science and society are shaped depending on local contingencies surrounding the pressing issues of the day and the audiences being addressed. In relation to the possible contribution current genetics research and bioweapons, there is much scope for considering how boundaries are maintained, undetermined, and negotiated in the professional standards held about basic/applied research, malign/benign applications, and the use/abuse of knowledge. For instance, the common overall framing of the dangers of biological weapons in terms the use and abuse of knowledge begs questions about how distinctions between these categories are made in practice. Expressed in this way, the important issues are ones of intent and purpose. The potential for unwittingly contributing to the basis for new weapons through otherwise legitimate research undermines this framing. Likewise in the current climate it is likely the boundaries of acceptability will be established in different ways than they were in the past.

A key question is how boundaries are established in the assessment of the appropriateness of research agendas and the proper conduct of individuals (see Rappert, 2001). Researchers outside of biodefense or dangerous pathogens networks might not have thought about, and on thinking about might not recognize as highly pertinent, the possible (prospective) malign utilization of their work by malicious users whose identity is ill defined. In organizational settings, the dangers and social demands of research are not likely to be matter of unanimity. There are highly complicated and dilemmatic questions about whether some forms of knowledge or research are more 'abusable' or 'dual-use' than others. Determinations of these will inform and depend on how various divisions are made between science and society, research and development, civil and military as well as biodefense and bio-offense. Yet, perhaps the resolution of these issues will not be nearly so divisive. As already suggested though, concerns about the potential abuses of biomedical research have been mitigated by claiming that the full release of information and the commissioning of 
extensive research will serve biodefense by stimulating new vaccines, treatments and diagnostics (e.g., Dennis, 2001).

\section{Norms}

As indicated previously, much of the discussion about the responsibilities of scientists as well the operation of research is couched in terms of the adherence to norms. Norms about the free exchange of research provide the basis for describing scientists' action, evaluating their conduct, and proscribing what course of action should be taken to mitigate national security concerns (e.g., the unfretted communication of research should continue). In the texts cited above and elsewhere, maintaining such norms and other scientific values is often said to require that researchers govern themselves. Science best serves society by defining and pursuing goals and standards determined by its members.

Expressed in this way, the understanding of norms shares much with Merton's (1973) functional analysis of science. He suggested certain normative requirements governed the search for certified knowledge in modern Western universities or basic research institutes. Merton and others working within this conceptual framework identified a number of these, including universalism (evaluating claims independently from personal characteristics), disinterestedness (refraining from personal gain), organized skepticism (always questioning the basis of facts), individualism (maintaining researcher autonomy in problem selection), and communalism (openly sharing and communicating discoveries). Such norms where said to exist as institutional imperatives that compelled certain behavior from scientists (or at least those who were part of the basic science community). Much worry has been voiced recently about the potential corrosive effects of national security requirements for communalism.

Given the prevalence of appeals to norms, how they can, do, or could influence agendas and practices are important questions. Sociologists of science such as Mulkay (1975) have given systematic critiques of 'norm governing' models of science. Empirical observation indicates norms are deviated from with an incredible frequency and they play little role in reward structures. With regard to communalism, for instance, scientists are not simply engaged in the unrestricted sharing of information. Rather secrecy is quite common and arguably functional. Scientists justify not communicating findings, releasing partial information, or imposing significant delays by claiming such acts help to minimize priority disputes, provide a basis for competition through the gaining restricted information, help establish the ultimate prestige of discoverers, enable the checking of results, and avoid possible misinterpretations by the press. Whether scientists even deem norms as relevant at all for evaluating their behavior in relation to particular circumstance is a source of contention (Gieryn, 1999). For Mulkay norms like universalism or disinterestedness might be adhered to on some occasions and they might provide standards for evaluating behavior in particular situations, but any conformity is highly negotiated. Such 'institutional imperatives' are 'better seen as a vocabulary of justifications, which 
are used to evaluate, justify and describe the professional actions of scientists but which are not institutionalized within the scientific community in such a way that conformity is maintained' (Mulkay, 1975, pp. 653-4). As with other aspects of social life, alternative presentations about norms provide a flexible vehicle for expressing (but not resolving) tensions with social life.

The last point raises the questions of just who gives just what portrayal of the conduct of scientists. Earlier writing by Mulkay and others drew attention to the potential ideological or public relations functions of accounts of norms. So those speaking for science might give downright 'misleading' portrayals in order to deflect calls for greater public interference. Similar disparities have been noted elsewhere in the study of science and technology. ${ }^{1}$

In relation to biological weapons, asking basic issues about how researchers communicate their work, evaluate these actions in relation to perceptions of 'community norms', and regard the types of claims made by spokesperson about the importance of ensuring the open and free sharing of research could be quite useful. Especially in light of recent terrorist actions, the terms of governance may be up for considerable redefinition. Arguably some degree of regulation might be seen as necessary to legitimize research. Irwin \& Wynne (1996) suggest that public attitudes to science depend on the trust placed in governing institutions. This trust is based on past experience and perceptions of current practices. Important questions arise then of what threats individual researchers and professional organizations perceive to the public acceptability of their research and how they actively reposition themselves in order to contend with anticipated challenges.

Additional concerns for future analysis stems from the metaphor that underlies discussions about restrictions on dissemination. This is something akin to water (knowledge) flowing out of a tap (science). The predominant casting of the issue of controls is how far one leaves open or closes the flow of research from certain pools of knowledge. Neatly outside of the bounds of this framing are commercial organizations where the presumption of unrestricted research is not often made. Moreover, since the norms of communalism are said to rule, there is no acknowledgement of the negotiations surrounding what research is shared, when and on what terms. The potential noted above for routine genetic engineering practices to contribute to weapon applications or for certain experiments to inadvertently highlight novel ways of furthering infectious diseases would suggest that scientists might be less than highly communicative about their research to those within or outside the biomedical communities.

In examining these issues about restrictions to research, insightful comparisons might be made with similar restrictions brought with the 'commodification of knowledge' (Kenney, 1986; Weil \& Snapper, 1989; Rappert \& Webster, 1997). As universities and governments have sought financial gain from publicly funded research, particularly in the last two decades, significant attempts have been made to foster links between industry and universities as well as gain intellectual property rights over research. These activities sit uneasily along side notions about university-based knowledge being freely available to all without 
care for personal gain. The benefits and costs associated with commercialization activities, such as restrictions on the sharing of information and techniques, have been ongoing topics of debate. As with questions about national security, high profile reports have been commissioned to investigate the matter (e.g., NAS, 1997). While determinations about the appropriateness of commercialization remains a matter of much local give and take, there can be little doubt about the centrality of this goal to science policy in the US and UK. The similarities and differences in the way restrictions are perceived or evaluated depending on national security or commercial justifications might help elaborate more fully how of 'norms' provide an elastic means of articulating tensions and justify actions.

This possible elasticity raises significant methodological and epistemological concerns. In a study of claims about discovery, contribution, originality, Gilbert \& Mulkay (1984) found scientists offered multiple and highly divergent accounts about how these should be understood. In asking, for instance, to what extent personalities or collegial politics figured into the unfolding the research agendas, individuals offered variable, context dependent and self-contradictory stories. Such differences were pronounced between accounts given in journals and interviews, but were also prevalent within individual interviews or responses to questions. The authors drew on the findings to suggest the meaning of social action is not 'a unitary characteristic of acts which can be observed as they occur, but as a diverse potentiality of acts that can be realized in different ways through participant's production of interpretations in different social contexts' (Gilbert \& Mulkay, 1984, p. 14). As such, trying to give a definitive version of what scientists really think about matters such as norms might well deny the manner in which such accounts are contextually dependent and produced.

Added to these points, there are further questions of orientation social analysts must face in examining biological weapons. Even if most public accounts of scientific norms offer little basis for understanding how biomedical communities function, there are pressing questions about what distinctions can be made between open dialogue versus more secretive practices. The centrality of norms in governing action might be a convenient fiction, but this need not lead to abandoning any attempts to promote openness or 'communalism'. This becomes apparent in deliberations about codes of conduct.

\section{Codes of conduct}

As with many other controversial topics or areas of potential dispute, in the case of biological weapons codes of conduct have been offered to ensure proper behavior. From mortgage lenders to engineering societies, the enactment of codes has long been associated with attempts to ensure the technical and moral quality of professional services. Sociologists and others typically have treated codes as part of attempts by professionals to ensure their autonomy and deflect away condemnation (Macdonald, 1995). Critical questions have been asked about if and how they function in practice as moral guides. 
In considering such issues, it first should be noted that professional codes differ significantly. Some lay down minimum standards of conduct, others are more aspiration in intent. That diversity in itself makes generalizing about their influence highly problematic. Certainly though cynicism has been expressed in the past regarding the purposes and promises of codes. Codes devoid of credible enforcement mechanisms in particular have been portrayed as pointless because those that act ethically do not need them and those that act unethically will not be deterred by them (see Coady \& Bloch, 1996).

In relation to biological weapons, interest in professional codes has been bound up with the BTWC. The prohibition against the development of bioweapons it mandated has been taken as establishing basic standards for those in biomedical communities. The professional responsibility suggested by the British Medical Association to reinforce the unacceptability of biological and genetic weapons through codes derives its basis from the BTWC. The UK government has proposed codes of conduct as one way of strengthening the Convention (HMSO, 2002). In November 2001 the US President George Bush (2001) announced a series of similar initiatives, including proposals to:

- Devise a solid framework for bioscientists in the form of a code of ethical conduct that would have universal recognition; and

- Promote responsible conduct in the study, use, modification, and shipment of pathogenic organisms.

The past ability of professionals in the Soviet Union, Iraq, and South Africa to violate the terms of the BTWC with seemingly little soul searching has led some to question the Convention's utility and thereby any codes of conduct. Defenders of the Convention such as Meselson (2000b) have treated the purpose of the proscriptions given as more varied than guaranteeing adherence. So the BTWC helps create a norm and that signals a symbolic commitment to addressing the problem of biological warfare. Moreover though, with widespread agreement in the prohibitions set out any violation of these would justify severe international condemnation and response. Finally, those in compliance of treaties such as the BTWC will find it difficult to turn a blind eye towards violations. Analyses of codes in other areas of professional conduct have likewise maintained that codes play a variety of roles beyond ensuring certain behavior-such as helping individuals re-interpret the situation facing them (Lichtenberg, 1996). Often, people do not reflect on the range of possible consequences of their actions and codes can force them to redescribe situations. Moreover, they generally heighten awareness of an issue (Freckelton, 1996). Taking all of these possible points on board, for those who are or are not engaged in biodefense work there are basic issues that need be asked about who has heard of weapons related norms and codes as well as how these are interpreted.

The importance of how codes are interpreted in specific circumstance becomes apparent when one examines the sort of advice now being given to practitioners. In 2001 the American Society of Microbiologist reaffirmed its 1985 code of ethics that discouraged 'any use of microbiology contrary to the 
welfare of humankind'. Of course, this provides preciously little in the way of specific instruction for those pondering the wisdom of biodefense-related research or the dilemmatic aspects of genetics research (e.g., how to cope with the offensive potential of otherwise legitimate research) discussed in the second section of Part I. What it does do is to push decision making down to the individual level, where a great deal of discretion can be exercised in how guidance is interpreted. The status of guidance as discretionary rather than rule-following is pervasive in many ethical codes (Coady \& Bloch, 1996). On the one hand, such discretion means judgments can be taken in a manner that is sensitive to the specific details of each situation. On the other hand, discretion also gives scope for justifying nearly any activity. In the case of the ASM, the indeterminacy of the guidance would seem a result of past divisive and unresolved disputes within the Society. Even as weak as the suggestions above are on their own, codes in practice combine with others principles (such as duty to country or scientific progress) that might undermine the force of any proscription. As such, merely gauging awareness or support for codes of conduct is of limited insight. A key question is how indeterminacies, dilemmas ambiguities are defined and interpreted in the assessment of the appropriateness of the proper conduct of individuals in organizational settings (Rappert, 2001).

At least in the past, the acceptability of activities potentially connected to biological weapons has not been treated simply as a matter of discretion. While there might be difficulties in classifying whether certain biodefense measures are allowed under the BTWC, there has been little disagreement that the production of biological weapons for warfare is prohibited. At yet, even this central tenet is being put up for 'negotiation'. In recent years there has been considerable interest in the US for so-called non-lethal weapons, including biological and chemical ones (Rappert, 2002). So, organizations such as the US Naval and the US Air Force's Armstrong Laboratory are seeking to promote genetically engineering microbial and biocatalysts that supposedly degrade materiels (such as runways or lubricants). Although such anti-material innovations have been ruled as falling foul of the BTWC by Naval Judge Advocate General, they continue under the justification of being 'non-lethal' (Sunshine Project, 2002a). Similar research projects are underway to assess the potential of psychopharmacological weapons as the next generation of human incapacitants (Sunshine Project, 2002b). These programs threaten to radically redefine notions of proper conduct vis-à-vis bioweapons in warfare by introducing a distinction between acceptable (read: 'non-lethal') and unacceptable ones. Just how those pushing for non-lethal weapons interpret codes regarding biological weapons would no doubt be a topic of considerable insight.

The antagonism likely to be generated from attempts to reinterpret international treaties as well as the scope for negotiation within organizations about the appropriateness of research agendas vis-à-vis codes of conduct highlights the fundamentally political basis of ethical codes. Pels (1999) provides an insightful account of the way in which morals become conceptualized and institutionalized through a consideration of codes of conduct. Drawing on the philosopher 
MacIntyre, he contends that while ethics are often treated as ruling over mere politics, ethical proscriptions are always threatened as being unmasked as essentially politically. The inter-dependence of the two raises questions about how they work in practice. Just how scientists are able to use the ethical standards spelled out in codes of conduct in particular situations depends on whether, for instance, the politics involved are treated as those between employer and employed or those between a professional and client. In the case of the latter, appeals to professionalism can further attempts to exercise autonomy, while in the former appeals to ethical principles are likely to give way to employee to employer obligations. In other words, any ethical escape from politics requires politics. For this reason the attempt to establish codes with universal recognition, as suggested above by George W. Bush, is likely to be elusive. ${ }^{2}$ Just how these matters are decided will depend on the position of scientists within society and to what extent they can draw on appeals to Truth to fend off particular forms of interference. In short, considering how codes operate requires addressing how ethics, politics and truth are conceptualized. These conceptualizations are part of the long-term history, social position and self-understanding of professions.

The commentary in this section about codes of conduct would suggest that those seeking to promote them as ways of minimizing the threats associated with biological weapons should first ask why this measure is being proposed and how it might tackle the issues at hand. It should be recognized that the type of ethical guidance being proposed risks either being platitudinous ('just do the right thing') or being challenged by policy developments. Those seeking to promote codes as ethical raising tools need to consider just how the dilemmatic and political issues associated with research that might have biological weapons implications can be acknowledged and addressed. If organizations and individuals recognize the limitations of codes, but carry on with proposing them as central pillars of reform for the biomedical community, then there are questions that need to be asked about the purposes sought.

\section{Summing up}

Recent terrorist acts in the US have heightened attention to the possibilities associated with bioattacks. This paper has outlined some of the difficulties and dilemmas associated with biomedical research, particularly with regard to genetics, and its potential contribution to biological weapons. Deliberations about proper policy responses in countries such the US and the UK entail conflicting representations about the severity of the threat faced and acceptability of regulatory measures. In this many problematic questions must be addressed about the distinction between offensive and defensive activities and the dual-use potential of current biomedical research. Whatever the ultimate policy outcome that forms in the future, it is clear the terms of reference for debate are in flux. Commenting on the place of biodefense research in the early 1990s Sprinkle (1992, p. 88) said: 
[o]nly the more adventurous life scientists believe in the prudence of bioweaponry research; few, if any, would advise bioweaponry development; none to my knowledge, advocates eventual bioweaponry development; and all, I assume, agree that bioweaponry use, in any circumstance, would be morally provocative, if not frankly inexcusable.

Recent events would suggest that this statement, if correct in the past, does not do justice to the extent of negotiation taking place today about where the boundaries of acceptable practice lie.

This paper has also argued the classification and distinction problems facing bioscientists pose dilemmas for those concerned with the analysis of the social, political, and ethical implications of genetics. If it can be said the possible weapon applications of genetics have been divorced from the core aims and agendas of research, much the same could this be said for social scientists. There are basic analytical and normative questions that it will be necessary to address regarding how divergent threat appraisals are assessed, what policy response measure are appropriate, and how ethical choices are made in conditions of uncertainty. The situation provides amble opportunity for the questioning methodology approaches and epistemological assumptions as the issues surrounding biological weapons are examined.

\section{Acknowledgements}

My thanks to Brian Balmer, Malcolm Dando and Gigi Kwik for their assistance in producing this paper.

\section{Notes}

1. Wynne (1998) has commented that discussions about many technologies are often characterized by a stark divide between the rule-bound images in public discussions and the contingencies and informal routines (even rule-breaking practices) prevalent in actions. Experts face many dilemmas as they try to reconcile the rule-bounded images of technology with the messy world of practice. Often this means that for public audiences, accidents or other problems are attributed to 'human error' or deviations from rules by operators even when the experts involved recognize the limitations of formalized rules in reflecting the operational practices.

2. I thank Brian Balmer for pointing out that such codes might still serve as boundary object across 'social worlds' and thus help (re-)orientate their behavior.

\section{References}

Alberts, B. (1999) Scientific openness and national security, Science, 285, p. 45.

Alberts, B. (2002) Engaging in a Worldwide Transformation: Our Responsibility as Scientists for the Provision of Global Public Goods, Presidential Presentation at the US National Academy of Sciences, 29 April (Washington, DC).

American Society for Microbiology (ASM) (2002) Biological Agents-Laboratory Safety, http:// www.asmusa.org/pcsrc/biolabsafety.htm

Atlas, R. (2001) Bioterrorism: The ASM Response, http://www.asmusa.org/pasrc/feature 1.htm

Balmer, B. (2002) Biological warfare, Medicine, Conflict and Survival, 18, pp. 120-37. 
British Medical Association (BMA) (1999) Biotechnology, Weapons and Humanity. (London: Harwood Academic Publishers).

Bush, G. (2001) President's Statement on Biological Weapons, 1 November, http:// www.whitehouse.gov/news/releases/2001/11/20011101.html

Cassell, G., Miller, L. \& Rest, R. (1994) Biological warfare: role of scientific societies. In Zilinskas, R. (ed) The Microbiologist and Biological Defense Research (New York: New York Academy of Science).

Coady, M. \& Bloch, S. (eds) (1996) Codes of Ethics and Professions (Sydney: Melbourne University Press).

Cunningham-Burely, S. \& Kerr, A. (1999) Defining the 'social', Sociology of Health E Illness, 21(5), pp. 647-68.

Dickson, D. (1984) The New Politics of Science (Chicago: University of Chicago Press).

Dennis, C. (2001) The bugs of war, Nature, 17 May, pp. 232-5.

Enserink, M. (2002) USDA loses lab doors to foreign scientists, Science, 10 May, p. 996.

Epstein, G. (2001) Controlling biological warfare threats, Critical Reviews in Microbiology, 27(4), pp. 321-54.

Federation of American Scientists (FAS) (2000) Controlling biological weapons, FAS Public Interest Report, 53, p. 5.

Freckelton, I. (1996) Enforcement of ethics. In Coady, M. \& Bloch, S. (eds) Codes of Ethics and Professions (Sydney: Melbourne University Press).

Gewin, V. (2002) Security worries stifle report on agricultural bioterror, Nature, 419, p. 99.

Gibbons, M. (1999) Science's new social contract, Nature, 402, pp. C81-C84.

Gieryn, T. (1995) Boundaries of science. In Jasanoff, S. et al. Handbook of Science and Technology Studies (London: Sage Publications).

Gieryn, T. (1999) Cultural Boundaries of Science (Chicago: University of Chicago Press).

Gilbert, N. \& Mulkay, M. (1984) Opening Pandora's Box (Cambridge: Cambridge University Press).

Halvorson, H. (1992) Civilian control of biological defense research. In Zilinskas, R. (ed) The Microbiologist and Biological Defense Research (New York: New York Academy of Science).

HMSO (2002) Strengthening the Biological and Toxin Weapons Convention (London: ]HMSO).

Irwin, A. \& Wynne, B. (1996) Misunderstanding Science? (Cambridge: Cambridge University Press).

Kadlec, R., Zelicoff, A. \& Vrtis, A. (1997) Biological weapons control, $\mathcal{F A M A , 2 7 8 , ~ p . ~} 5$.

Kenney, M. (1986) Biotechnology: The University-Industry Complex (New Haven: Yale University Press).

Knobler, S., Mahmoud, A. \& Pray, L. (eds) (2002) Biological Threats and Terrorism (Washington, DC: National Academy Press).

Lancet Infectious Diseases (2001) Too much learning is a dangerous thing, Lancet Infectious Diseases, 1, p. 287.

Lichtenberg, J. (1996) What are codes of ethics for? In Coady, M. \& Bloch, S. (eds) Codes of Ethics and Professions (Sydney: Melbourne University Press).

Macdonald, S. (1995) The Sociology of the Professions (London: Sage).

Malakoff, D. (2001) The year of living dangerously, Science, 294, p. 2443.

Malakoff, D. (2002a) Spending triples on terrorism R\&D, Science, 295, p. 254.

Malakoff, D. (2002b) Tighter security reshapes research, Science, 297, pp. 1630-3.

Malakoff, D. (2002c) Congress homes in on new department's R\&D programs, Science, 297, pp. 912-3.

Marshall, E. (1997) Too radical for NIH? Science, 275, pp. 744-6.

Merton, R. (1973) The normative structure of science. In Storer, N. (ed) The Sociology of Science (Chicago: University of Chicago Press).

Meselson, M. (1989) Statement before the Senate governmental affairs committee and its permanent subcommittee on investigations, 17 May, quoted in Zilinskas, R. \& T. Wilson 


\section{Brian Rappert}

(1992) Introduction. In Zilinskas, R. (ed) The Microbiologist and Biological Defense Research, pp. xiii-xiv (New York: New York Academy of Science).

Meselson, M. (2000a) Averting the exploitation of biotechnology, FAS Public Interest Report, 53, p. 5.

Meselson, M. (2000b) The Problem of Biological Weapons. Presented at AAAS Annual Meeting, 17-22 February (Washington, DC).

Mulkay, M. (1975) Norms and ideology in science, Social Science Information, 15(4/5), pp. $637-56$.

National Academy of Science (NAS) (1997) Intellectual Property Rights and Research Tools in Molecular Biology (Washington, DC: National Academy Press).

National Commission on Terrorism. (2001) Countering the Changing Threat of International Terrorism (Washington, DC: National Commission on Terrorism).

National Institute of Allergy and Infectious Diseases (NIAID) (2002) NIAID Strategic Plan for Biodefense Research (Washington, DC: National Institute of Allergy and Infectious Diseases).

Pels, P. (1999) Professions of duplexity, Current Anthropology, 40(2), pp. 101-14.

Poste, G. (2001) A rude awakening to the forces of good and evil, Financial Times, 27 November, iv.

Rappert, B. (2002) Technology, Politics and Conflict (London: Frank Cass).

Rappert, B. (2001) The distribution and resolution of the ambiguities of technology, Social Studies of Science, 31(4), pp. 557-92.

Rappert, B. \& Webster, A. (1997) Regimes of ordering: the commercialisation of intellectual property in industrial-academic collaboration, Technology Analysis and Strategic Management, 9(2), pp. 115-30.

Relyea, H. (1994) Silencing Science (Norwood, NJ: Ablex Publishing).

Sprinkle, R. (1992) Bioweaponry and 'life-science liberalism'. In Zilinskas, R. (ed) The Microbiologist and Biological Defense Research (New York: New York Academy of Science).

Steinbruner, J. (2000) Principles of Global Security (Washington, DC: Brookings Institute).

Stone, R. (2002) US visa crackdown disrupts meetings, Science, 23 August, p. 1259.

Sunshine Project (2002a) US Armed Forces Push for Offensive Biological Weapons Development, 8 May (Hamburg: The Sunshine Project).

Sunshine Project (2002b) Pentagon Program Promotes Psychopharmacological Warfare (Hamburg: The Sunshine Project).

United States Department of State (2002) Bush Strategy to Defend Against Bioterrorism, US Department of State Fact Sheet, 5 February.

United States National Security Decision Directive 189 (1985) National Policy on the Transfer of Scientific, Technical, and Engineering Information, 21 September.

Verhoog, H. (1981) The responsibility of scientists, Minerva, 19, Winter, pp. 587-602.

Weil, V. \& Snapper, J. (eds) (1989) Owning Scientific and Technical Information (Rutgers: Rutgers University Press).

Wheelis, M. (2001) Deterring bioweapons development, Science, 291, p. 2089.

Wright, S. (ed) (1990) Preventing A Biological Arms Race (Cambridge, MA: MIT Press).

Wynne, B. (1998) Unruly technology: practical rules, impractical discourses and public understanding, Social Studies of Science, 18(1), pp. 147-67.

Zilinskas, R. (ed) (1992) The Microbiologist and Biological Defense Research (New York: New York Academy of Science).

Zilinskas, R. \& Wilson, T. (1992) Biological Weapons. In Zilinskas, R. (ed) The Microbiologist and Biological Defense Research (New York: New York Academy of Science). 